\title{
The effects of estradiol on food intake and weight in ovariectomized rats with amygdaloid lesions*
}

\author{
VERNE C. COX and JAMES M. KING \\ University of Texas at Arlington, Arlington, Texas 76019
}

\begin{abstract}
The effects of estradiol on increased food intake and body weight gain induced by ovariectomy. were examined in rats with lesions of the cortical and medial amygdaloid nuclei. Lesioned animals displayed typical ovariectomy-induced hyperphagia and weight gain. Estradiol injections were effective in maintaining normal food intake and weight gain in ovariectomized lesioned animals.
\end{abstract}

Estrogens play an important role in the regulation of food intake and body weight in female rats. Food intake is highest during anestrus and lowest during estrus, when estrogenic effects are at their lowest and highest levels, respectively (Shaikh, 1971; Tarttelin \& Gorski, 1971). Jennings (1973) has recently reported that behavioral measures of food motivation also vary during the estrous cycle, with greatest inhibition of food motivation evident during estrus. Ovariectomy induces increased food intake and weight gain which can be reversed by administration of estradiol (King \& Cox, 1973; Zucker, 1972). The anorexic properties of estrogens are modulated by body weight and are greater at supranormal body weight levels (Meites \& Reed, 1949; Redick, Nussbaum, \& Mook, 1973; Zucker, 1972). Previous work has suggested that estrogenic modulation of food intake and body weight is mediated via the ventromedial hypothalamic nucleus (VMHN) (Wade \& Zucker, 1970). However, recent work in our laboratory has indicated that food intake and weight suppression by estradiol is unimpaired following VMHN lesions (King \& Cox, 1973). Consequently, our attention has been directed to other central nervous system sites that might participate in estrogenic modulation of food intake and body weight.

In the present study, we chose, for two reasons, to examine the corticomedial (CM) nuclear group of the amygdala. First, this area has been implicated in food-intake regulation (Collier \& Gault, 1969; Kaada, 1972; Sclafani, Belluzzi, \& Grossman, 1970; Singer \& Montgomery, 1968). Stimulation of the CM amygdaloid nuclei yields facilitation of feeding behavior, whereas lesions typically yield no change or disruption of feeding behavior (cf. Kaada, 1972). Secondly, the CM group displays a high level of estradiol uptake (Pfaff \& Keiner, 1973; Stumpf, 1972). The CM group has direct connections, via stria terminalis, as well as multisynaptic connections with numerous diencephalic sites, including the VMHN, medial preoptic area, septal nuclei, and the

*This research was supported, in part, by the Organized Research Fund of the University of Texas at Arlington. Reprint requests should be sent to Verne C. Cox or James M. King, Psychology Department, University of Texas at Arlington, Arlington, Texas 76019. bed nucleus of stria terminalis (Heimer \& Nauta, 1969; Lammers, 1972; de Olmos \& Ingram, 1972). Previous work in our laboratory indicates that any CM amygdaloid mediation of estrogenic effects on food intake and weight regulation would not be dependent upon CM-VMHN connections (King \& Cox, 1973). However, the numerous other diencephalic connections of the CM group suggested the possibility that estrogenic modulation of food intake and body weight might be mediated by the CM nuclear group of the amygdala. The present study examined the effects of estradiol on ovariectomy-induced hyperphagia and weight gain in female rats with lesions of the CM nuclear group of the amygdala.

\section{METHOD}

\section{Subjects}

The Ss were female albino rats of the Holtzman strain $(245-265 \mathrm{~g})$. They were housed in individual cages and maintained on powdered Purina lab chow and tap water. A 12-h light-dark cycle was maintained in the animal quarters.

\section{Procedure}

Preoperative measurements of food intake and body weight were obtained for 10 days. On the day of surgery, all animals were anesthetized with a mix ture of chloral hydrate and sodium pentobarbitol (Equithesin) and were administered bilateral lesions of the CM nuclear group of the amygdala. With the skull level between bregma and lambda, the tip of the lesion probe was placed $2 \mathrm{~mm}$ posterior to bregma, $3.5 \mathrm{~mm}$ lateral to the midline, and $9 \mathrm{~mm}$ below the surface of the skull. The anodal current employed was $1 \mathrm{~mA} \mathrm{dc}$, applied for $30 \mathrm{sec}$. The experiment employed three groups of animals with amygdaloid lesions. They were preoperatively matched for body weight and food intake. Animals in one group (OVX-EB) were ovariectomized and lesioned, and they received daily postoperative subcutaneous injections of 1.5 micrograms estradiol benzoate (EB) in $.10 \mathrm{ml}$ of sesame oil. In a second group (OVX-OIL), animals were ovariectomized and lesioned, and they received daily injections of sesame oil. The third group (INTACT-OIL) consisted of animals that received bilateral flank incisions, lesions, and daily injections of sesame oil.

Following surgery, food intake and body weight measurements were obtained for 25 days. At the conclusion of the experiment, the animals were sacrificed with an overdose of anesthetic and perfused intracardially with .9\% saline and $10 \%$ Formalin. Their brains were removed, and frozen sections, 60 microns thick, were stained with cresylecht violet and examined microscopically to determine the extent and location of the lesions. 


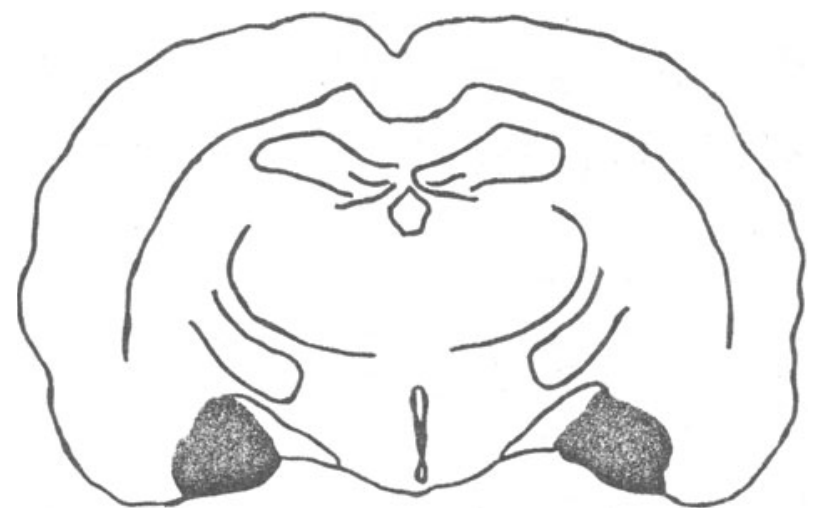

Fig. 1. Camera lucida drawing of representative amygdala lesions.

\section{RESULTS}

\section{Histology}

Each of the three groups consisted of eight animals that met histological criteria for complete symmetrical bilateral destruction of the cross-sectional area of the medial and cortical amygdaloid nuclei with minimal damage to the basolateral amygdaloid group. Figure 1 illustrates maximal cross-sectional damage of representative amygdala lesions. Total cross-sectional damage extended, in most cases, throughout the entire anterior-posterior extent of the CM amygdaloid nuclei and corresponded to areas represented on Plates 30-35 of the stereotaxic atlas by Konig and Klippel (1963).

\section{Food intake and Body Weight}

Figures 2 and 3 present the percentage-change values for food intake and body weight for the three groups. The percentage-change scores are relative to the mean of the last 5 preoperative days for food intake and the last preoperative day for body weight. Absolute difference scores for food intake and body weight are presented in Table 1. The magnitude of ovariectomy-induced hyperphagia and weight gain in oil-treated lesioned animals was comparable to that observed previously in nonlesioned ovariectomized rats (King \& Cox, 1973). Analysis of variance applied to the mean food intake

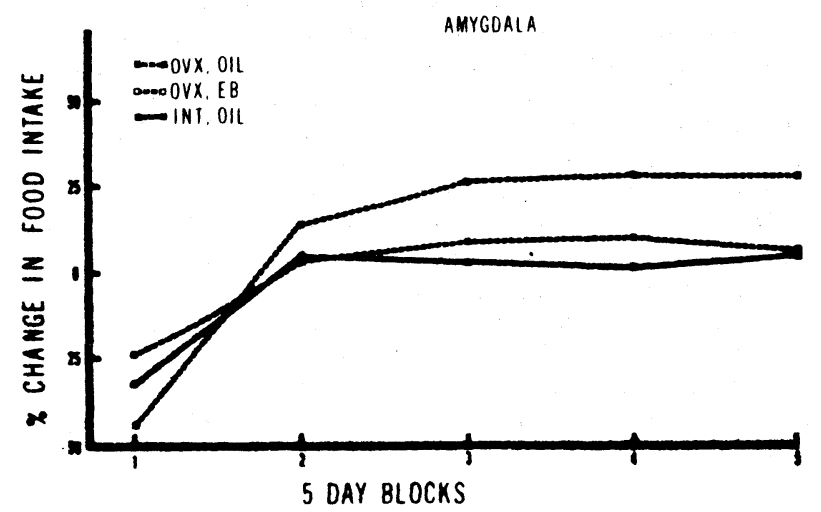

Fig. 2. Percentage change in food intake.

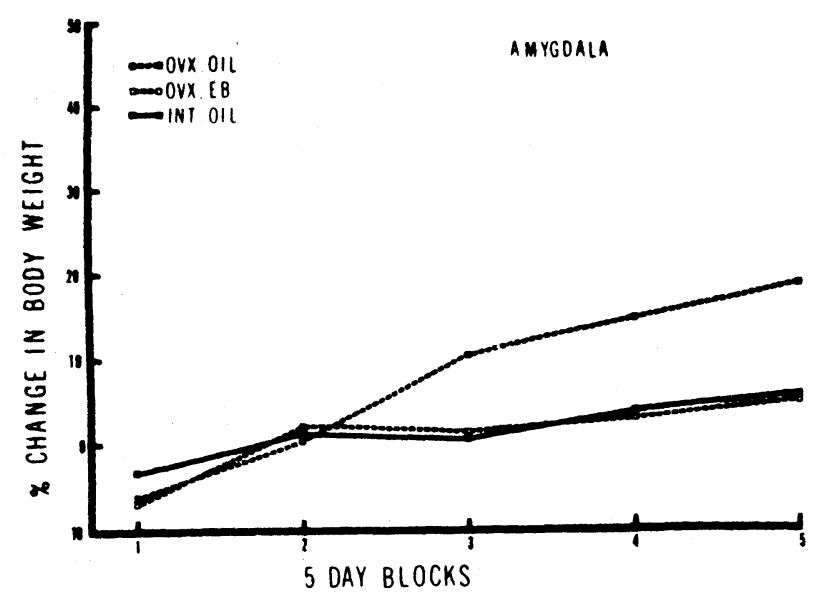

Fig. 3. Percentage change in body weight.

values for the last 5-day postoperative period for each group yielded a significant effect, $F(2,21)=37.42$, $\mathrm{p}<.05$. A similar analysis applied to the body weight values of the last postoperative day also yielded a significant effect, $F(2,21)=63.37, p<.05$. Estrogen treatment yielded complete suppression of ovariectomy-induced hyperphagia and weight gain. There were no statistically reliable preoperative differences in body weight or food intake among the three groups.

\section{DISCUSSION}

The results of the present study indicate that estrogenic modulation of food intake and body weight gain is not dependent upon the integrity of the $\mathrm{CM}$ amygdaloid nuclei. These findings are similar to those obtained with ventromedial hypothalamic lesions (King \& Cox, 1973). These two studies do not exclude the possibility that direct central nervous system estrogenic modulation of food intake and weight gain is mediated via a redundant system involving multiple estrogen-sensitive sites. Such a system might include the VMHN, CM amygdala group as well as other estrogen-sensitive central nervous system sites, such as the preoptic area, the bed nucleus of stria terminalis, and the septum (Anderson \& Greenwald, 1969; Pfaff \& Keiner, 1973; Stumpf, 1970). At this point, it would not appear necessary to assume that estrogenic modulation of food intake and weight gain involves CNS sites specifically involved in food intake and weight regulation. The widespread uptake of estradiol within the pituitary (Anderson \& Greenwald, 1969) and hypothalamus (Pfaff \& Keiner, 1973) offers the possibility of direct and indirect estrogenic modulation of tropic hormone secretion that might, in turn, influence food intake and weight gain. For example, D'Angelo and Fisher (1969) have reported estrogenic influences on thyroid-stimulating hormone secretion, and Richard (1966) has reported that estrogens affect adrenocorticotropic hormone secretion. However, in the case of the adrenal system, Redick et al have 
Table 1

Mean Changes in Body Weight and Daily Food Intake in Grams

\begin{tabular}{lcccccc} 
Group & $\begin{array}{c}\text { Preoperative } \\
\text { Weight }\end{array}$ & $\begin{array}{c}\text { Postoperative } \\
\text { Weight }\end{array}$ & $\begin{array}{c}\text { Net } \\
\text { Change }\end{array}$ & $\begin{array}{c}\text { Preoperative } \\
\text { Food }\end{array}$ & $\begin{array}{c}\text { Postoperative } \\
\text { Food }\end{array}$ & $\begin{array}{c}\text { Net } \\
\text { Change }\end{array}$ \\
\hline OVX, OIL & 256 & 319 & 63 & 17.0 & 21.7 & 4.7 \\
OVX, EB & 255 & 264 & 9 & 16.2 & 17.6 & 1.4 \\
INT, OIL & 255 & 268 & 13 & 17.4 & 18.3 & 0.9 \\
\hline
\end{tabular}

reported that adrenalectomy does not block the estrogenic suppression of food intake and weight gain in ovariectomized rats. Posterior pituitary hormones are also affected by estrogens via their effects on follicle-stimulating and luteinizing hormones, which, in turn, influence posterior pituitary hormones (Swaab \& Jongkind, 1971). These findings may account for at least part of the absolute increase in carcass water content observed in ovariectomized females (Leshner \& Collier, 1973). Moreover, the possibility of peripherally mediated estrogenic effects on food intake and weight gain cannot be excluded (Davidson, 1971). For example, Herbai (1971) has reported evidence indicating estrogenic suppression of growth hormone effects on bone growth at peripheral sites of action of growth hormone. Similarly, Costrini and Kalkhoff (1971) and Matute and Kalkhoff (1973) have reported estrogen-induced hyperinsulinemia. Woods, Decke, and Vasselli (1974) have recently argued that the ratio of insulin to growth hormone plays a major role in body weight regulation. Consequently, the effects of estrogens on insulin and growth hormone may be an important factor in estrogenic modulation of body weight and food intake.

In summary, our work thus far has failed to implicate two central nervous system sites that have demonstrated high uptake of estradiol and have also been implicated in food intake regulation in the estrogenic modulation of food intake and body weight. Consequently, we have been encouraged to examine other alternatives, including peripheral mechanisms through which estrogens might influence food intake and body weight regulation.

\section{REFERENCES}

Anderson, C. H., \& Greenwald, G. S. A utoradiographic analysis of estradiol in the brain and pituitary of the female rat. Endocrinology, 1969, 85, 1160-1165.

Collier, B. D.. \& Gault, F. P. Aphagia and adipsia following lesions of the amygdala. Psychonomic Science, 1969, 17, 41-42.

Costrini, N. V., \& Kalkhoff, R. K. Relative effects of pregnancy, estradiol, and progesterone on plasma insulin and pancreatic islet insulin secretion. Journal of Clinical Investigation, 1971, 50, 992-999.

D'Angelo, S. A., \& Fisher, J. S. Influence of estrogen on the pituitary-thyroid system of the female rat: Mechanisms and loci of action. Endrocrinology, 1969, 84, 117-122.

Davidson, J. M. Overview and summary of conference. In C. H Sawyer and R. A. Gorski (Eds.), Steroid hormones and brain function. Berkeley: University of California Press, 1971.

de Olmos, J. S., \& Ingram, W. R. The projection field of the stria terminalis in the rat brain: An experimental study. Journal of Comparative Neurology, 1972, 146, 303-334.

Heim er, L., \& Nauta, W. J. H. The hypothalamic distribution of the stria terminalis in the rat. Brain Research, 1969, 13, 284-297.
Herbai, G. Studies on the site and mechanism of action of the growth inhibiting effects of estrogens. Acta Physiologica Scandinavia, 1971, 83, 77-90.

Jennings, W. A. Estrus anorexia: Single-tube intake and bar-press rate in the albino rat. Physiological Psychology, 1973, 1, 369-372.

Kaada, B. R. Stimulation and regional ablation of the amygdaloid complex with reference to functional representations. In B. E. Eleftheriou (Ed.), The neurobiology of the amygdala. New York: Plenum Press, 1972.

King, J. M., \& Cox, V. C. The effects of estrogens on food intake and body weight following ventromedial hypothalamic lesions. Phy siological Psy chology, 1973, 1, 261-264.

Konig, F. R., \& Klippel, R. A. The rat brain: A stereotaxic atlas of the forebrain and lower parts of the brain stem. Baltim ore: Williams \& Wilkins, 1963.

Lammers, $H$. J. The neural connections of the amygdaloid complex in mammals. In B. E. Eleftheriou (Ed.), The neurobiology of the amygdala. New York: Plenum Press, 1972.

Leshner, A. I., \& Collier, G. The effects of gonadectomy on the sex differences in dietary self-selection patterns and carcass compositions of rats. Physiology \& Behavior, 1973, 11 , 671-676.

Matute, M. L., \& Kalkhoff, R. K. Sex steroid influence on hepatic gluconeogenesis and glycogen formation. Endocrinology, 1973,92, 762-768.

Meites, J., \& Reed, J. O. Relation of food intake to growth-depressing action of natural and artificial estrogens. American Journal of Physiology, 1949, 159, 281-286.

Pfaff, D., \& Keiner, M. Atlas of estradiol-concentrating cells in the central nervous system of the female rat. Journal of Comparative Neurology, 1973, 151, 121-158.

Redick, J. H., Nussbaum, A. I., \& Mook, D. G. Estradiol induced suppression of feeding in the fem ale rat: Dependence on body weight. Physiology \& Behavior, 1973, 10, 543-547.

Richard, R. Estrogen effects on pituitary-adrenal function via the hypothalamus and hypophysis. Neuroendocrinology, $1966,1,322-332$.

Sclafani, A., Belluzzi, J. D., \& Grossman, S. P. Effects of lesions in the hypothalamus and amygdala on feeding behavior in the rat. Journal of Comparative \& Physiological Psychology, $1970,72,394-403$.

Shaikh, A. H. Estrone and estradiol levels in the ovarian venous blood from rats during the estrous cycle and pregnancy. Biology of Reproduction, 1971, 5, 297-307.

Singer, G., \& Montgomery, R. B. Neurohumoral interaction in the rat amygdala after central chemical stimulation. Science, 1968. 160. 1017-1018.

Stumpf, W. E. Estrogen-neurons and estrogen-neuron systems in the periventricular brain. American Journal of Anatomy, 1970, 129, 207-217.

Stumpf, W. E. Estrogen, androgen, and glucocorticosteroid concentrating neurons in the amygdala, studied by dry autoradiography. In B. E. Eleftheriou (Ed.), The neurobiology of the amygdala. New York: Plenum Press, 1972.

Swaab, D. F., \& Jongkind, J. F. Influence of gonadotropic hormones on the hypothalamic neurosecretory activity in the rat. Neuroendocrinology, 1971, 8, 36-47.

Tarttelin, M. F., \& Gorski, R. A. Variations in food and water intake in the normal and acyclic female rat. Phsyiology \& Behavior, 1971, 7, 847-852.

Wade, G. N., \& Zucker, I. Modulation of food intake and locomotor activity in female rats by diencephalic hormone implants. Journal of Comparative \& Physiological Psychology. 1970, $72,328-336$.

Woods, S. C., Decke, E., \& Vasselli, J. R. Metabolic hormones and regulation of body weight. Psychological Review, 1974, 81, 26-43.

Zucker, I. Body weight and age as factors determining estrogen responsiveness in the rat feeding system. Behavioral Biology, $1972,7,527-542$.

(Received for publication April 4, 1974; revision received May $23,1974$. 